\title{
Anti-Psychologism and Neutrality
}

The Radical Empiricism of Husserl and James

\section{Roberta Lanfredini}

\section{CpenEdition}

\section{Journals}

Electronic version

URL: http://journals.openedition.org/ejpap/999

DOI: 10.4000/ejpap.999

ISSN: 2036-4091

Publisher

Associazione Pragma

Electronic reference

Roberta Lanfredini, « Anti-Psychologism and Neutrality », European Journal of Pragmatism and American Philosophy [Online], IX-1 | 2017, Online since 22 July 2017, connection on 21 December 2020. URL:

http://journals.openedition.org/ejpap/999 ; DOI : https://doi.org/10.4000/ejpap.999

This text was automatically generated on 21 December 2020 .

\section{(c) $(1) \odot$}

Author retains copyright and grants the European Journal of Pragmatism and American Philosophy right of first publication with the work simultaneously licensed under a Creative Commons AttributionNonCommercial-NoDerivatives 4.0 International License. 


\title{
Anti-Psychologism and Neutrality
}

\author{
The Radical Empiricism of Husserl and James
}

\author{
Roberta Lanfredini
}

\section{Anti-Psychologism and Anti-Realism in Husserl}

1 As is well known, Husserl's criticism of psychologism is unreserved. Psychologism, understood as a tendency to attribute any claim of rational validity to the structure of the human psyche, or to its biological and psychic base, confines logic entirely to psychology. Following psychologism's reasoning to its extremes, we would have to acknowledge that the distinction between rational thought and judgement depends only on the psychic constitution which, de facto, characterises us. This means that if this constitution were different, we would have other forms of reasoning and would even perceive in another way than we do. In short, we would live in a different world. From such a perspective, justifying a logical principle means understanding mental processes which occur when it is thought: for example, the principle of contradiction would not express the condition of possibility of any true utterance, but a psychological impossibility. We cannot believe two contradictory things at the same time, simply because two opposed belief-acts cannot coexist in our mind. ${ }^{1}$ The cogency of the principle of non-contradiction would not therefore reside in a presumed absolute validity, but in a factual impossibility, due to a certain structure or mental constitution, of thinking otherwise. To the extent that it reduces the validity of concepts to the subject's bio-psychic structure, psychologism is also inevitably subjectivism and relativism: to say that something is true in relation to a biological or psychic structure means admitting that this something could not be true for someone endowed with a different structure. In the end, psychologism is scepticism: if nothing exists but points of view determined by different de facto constitutions, there will be no objective point of view. Now, for Husserl, the basic error of psychologism is that of deducing logical principles from facts. Psychologism, as a form of scepticism, is not only false for Husserl, but absurd. In fact, it

makes the assertion: anything is true for a given species of judging beings that, by their constitution and laws of thought, must count as true. This doctrine is absurd. 
For it is part of its sense that the same proposition or content of judgment can be true for a subject of the species homo, but may be false for another subject of a differently constituted species. The same content of judgement cannot, however, be both true and false: this follows from the mere sense of "true" and "false." If the relativist gives these words their appropriate meaning, his thesis is in conflict with its own sense. (Husserl 1899-1900a/1973: 79)

2 So, psychologism misunderstands the very meaning of the term, "truth," since this term does not allude to a subjective belief but to an objective validity. The absurdity into which it runs could be rendered as an assertion of the type, "it is true that there is no such thing as truth." The declaration of scepticism's absurdity is linked to another absurdity: that of the thing in itself. For Husserl (and for Kant before him), this is neither syntactical nonsense nor semantic nonsense. Speaking of an absolutely independent and objective thing, is not in fact contradictory. The thing in itself does not even express a material self-contradiction: speaking of a thing in itself is not like speaking of a colour without extension. According to Husserl, the thing in itself expresses a formal self-contradiction, something like a round square. The reason would reside in the fact that the expression "in itself" contradicts the expression "thing": in other words, the notion of thing in itself contains determinations which challenge one another irreconcilably. The self-contradiction would be something like a world outside of our world; and yet, on a closer view, a world outside our world is not only, as Husserl admits, different from a thing that is simultaneously green and not green (which in this case would sound like something of the type world not-world); but also - in contradiction to what Husserl maintains - from round square (something like real-appearance). The fact that we are talking about a further type of self-contradiction is indicated by the word outside associated with the word our, in the assertion "a world outside of our world."

The hypothetical assumption of something real outside this world is, of course, "logically" possible; obviously it involves no formal contradiction. But when we ask about the essential conditions on which its validity would depend, about the mode of demonstration taken universally essentially determined by the positing of something transcendent [...] we recognize that something transcendent necessarily must be experienceable not merely by an Ego conceived as an empty logical possibility but by any actual Ego as a demonstrable unity relative to its concatenations of experiences. (Husserl 1913/83: 108)

Referring to a world outside our world, and so to the thing in itself, does not entail the violation either of the material ontological law according to which two genera that are founded in experience, become separated from each other (as in the case of colour and extension), or of the formal ontological law which states that two disconnected species cannot live together within the same singularity (as in the case of square and round). In the case of the thing in itself, we are witnessing the violation of a further, and in a certain sense, prior law: the law according to which the notion of thing necessarily refers back to a lived experience. Note: reference to, not belonging to. Indeed, red does not contain the sensation of red and conversely, the sensation of red does not contain red as its constituent part. Nevertheless, red refers back to the sensation of red, just as the red house refers back to the perception of the red house. The ontological-material self-contradiction (colour without extension) and the ontological-formal selfcontradiction (round-square) make reference to the bondedness in force between the non-independent parts of the thing: foundation in the first case (colour and extension are genera founded on one another) and inclusion in the second (two species belonging concretely to the same genus become disconnected). The expression 'thing in itself' 
expresses a self-contradiction which we could call formal-constitutive. This is a selfcontradiction which appeals not so much to the internal structure of the thing, so much as to its necessary link - in that it is a thing - to an experience. The thing in itself is therefore self-contradictory because it makes reference to something that contains the reference to consciousness while at the same time withdrawing from it: it is simply not something. If the two concepts of object and experience are separate genera linked by a relationship of unilateral foundation, ${ }^{2}$ the notion of thing in itself represents a violation of this type of foundation.

The necessary link between object and experience guarantees neutrality to phenomenology and at the same time ensures that it renders psychologism obsolete. In Husserl, these two concepts, of neutrality and anti-psychologism, go hand in hand. In fact, anti-psychologism is an immediate consequence of the work of neutralization (or of reduction, suspension, modification, epoché, placed in brackets: all of these terms being considered synonyms by Husserl) which allows phenomenology to convert into phenomenological and eidetic giveness all that is given naturally (or naturalistically) as a de facto datum. This conversion also concerns concrete psychic activity: from being empirical, it becomes transformed into structures of eidetic consciousness. What phenomenology aims at is not so much the individual consciousness as its essential structure. Descriptive analysis of the states of consciousness does not mean investigation of the psycho-physical causes which determine the origin of our experiences. Phenomenology does not describe the experience as rooted in a particular organism in a determined situation, nor is it concerned with psychological regularities founded on human nature (as was the case in Hume, for example); it does not consider the psychological genesis or the organic origin of lived experience as being within its remit. What phenomenology offers is a pure analysis of consciousness, which satisfies two conditions: investigating the internal structure of experiences and investigating their invariant, or essential, structure. The search for invariance therefore extends to all phenomena, including experiences. On the other hand, conceiving of phenomenology as the investigation of essences does not deny the absolute priority of subjectivity: the invariant structures of experience and of the objects which reveal themselves in such experience are structures of subjectivity, or rather are constituted by subjectivity, not structures which the objects would exhibit in themselves and for themselves. In this sense, phenomenology proposes itself as a transcendental investigation: the objects towards which the experiences of consciousness are intentionally directed always and necessarily pertain to subjectivity. Any reference to entities that are not the result of such a constitution must be "neutralized" by the phenomenological method, using the instrument of the epoché, whose purpose is to put belief in the effective existence of the world in brackets. This permits an interruption of the naïve adherence to reality which marks natural behaviour, that same adherence which is then reversed in the naturally (or naturalistically) oriented positive sciences.

\section{Which Neutrality?}

5 Every phenomenon necessarily refers back to an experience. The latter must nevertheless be interpreted not as a psychic phenomenon, but as an eidetic phenomenology; that is, as having a structure that is not psychological and individual, but essential and universal. These two assertions enclose the idea of phenomenology as 
a science of experiences which is as the same time anti-psychologist and neutral. Hence, the notion of neutrality reaffirms the link with the operations of subjectivity, albeit transformed eidetically. Now, it is exactly the notion of neutrality which is deactivated by James, in favor of an almost inverted interpretation of this concept. The result will be a conception radically different from anti-psychologism, which is nevertheless maintained within the sphere of a "pure" description of experience, of what we could without hesitation call a phenomenological description.

Both Husserl and James, therefore, identify neutrality as the way to realize that "radical standing by experience" (James 1907/96: 23), which distinguishes a radical (and sophisticated) empiricism. The problem is that the notion of neutrality has by no means the same meaning for one as it does for the other. For Husserl, as we have seen, adopting a neutral stance means maintaining a transcendental system, the keys of which are as follows: constitution, noesis, content, intentional structure. In other words, an asymmetrical structure which, declaring the priority of the noetic pole over the noematic, at the same time asserts the priority of the cognitive stance. Neutralization, understood as suspension, modification, or bracketing, is therefore substantially directed towards natural behavior with a view to asserting the fundamentality of the subjective pole over the objectival one. For James, adopting a neutral stance means, on the contrary, not so much reducing or modifying the natural world, or putting it in brackets, as adopting a methodological stance of symmetry and equidistance. So for James, contra Husserl, neutrality entails the obsolescence of two theses: the first is the thesis of the consciousness "as an 'epistemological' necessity" (James 1907/96: 7), which gives absolute priority to the gnoseological stance ('“'Consciousness' is supposed necessary to explain the fact that things not only are, but get reported, are known" James 1907/96: 6), the second is the thesis of the phenomenological necessity of reflection, understood as immanent intentionality, which Husserl considers necessary to guarantee the - so to speak - retroactive mechanism of neutralization. Reflection is assimilated by James to a

thoroughly ghostly condition, being only a name for the fact that the 'content' of experience is known. It loses personal form and activity - these passing over to the content - becomes a bare Bewusstheit or Bewusstsein überhaupt, of which in its own right absolutely nothing can be said. I believe that 'consciousness,' when once it has evaporated to this estate of pure diaphaneity, is on the point of disappearing altogether [...]. The moment we try to fix our attention upon consciousness and to see what, distinctly it seems to vanish. It seems as if we had before us a mere emptiness. When we try to introspect the sensation of blue, all we can see is the blue; the other element is as if it were diaphanous. (James 1907/96: 6-8)

7 "Ghostly condition," "diaphaneity," "pure echo," "feeble noise," “a kind of impalpable inner flowing" (James 1907/96: 8): all these expressions are potentially directed towards Husserl's reflective system, in an attempt to diminish its efficacy and its descriptive artificiality: "we are supposed by almost every one to have an immediate consciousness of consciousness itself" (James 1907/96: 7); "if you abstract the content, the consciousness will remain revealed to its own eye" (James 1907/96: 8).

For James, a pragmatist (or neutral) methodology has the aim of challenging both the predominance of knowledge and the efficacy of reflection: in other words, the two pillars of Husserl's asymmetrical system. The result is the identification of a totally equidistant and impersonal terrain in which pure experience dwells: 
My thesis is that if we start with the supposition that there is only one primal stuff or material in the world, a stuff of which everything is composed, and if we call that stuff 'pure experience,' then knowing can easily be explained as a particular sort of relation towards one another into which portions of pure experience may enter. The relation itself is a part of pure experience; one of its "terms" becomes the subject or bearer of the knowledge, the knower, the other becomes the object known. (James 1907/96: 7)

9 The goal is a dualism that is no longer bipolar (ie. expressed in the asymmetry of experience-phenomenon, consciousness-datum) but unipolar (expressing itself in the ontological indifference of the terms "thought," "thing," or "idea," as understood by classical empiricist tradition; a "unipolar dualism"3 in which the distinction between consciousness and "content" (in the sense of intended phenomenon) is not given by subtraction (as in Husserl), but by addition. ${ }^{4}$ Proceeding by addition means adopting the perspective of a neutral but dual monism, within which experience takes on the likeness of subjective or objectival experience, according to the context into which it happens to be inserted. Thought and thing, consciousness and phenomenon, noesis and noema (to use Husserl's terminology) are therefore not ontologically but functionally distinct: in other words, the distinction between them does not depend on internal but external factors; that is, on being inserted into different relational contexts. This allows experience to assume a sort of interchangeability which alone is able to satisfy fully the requirement of "neutrality." The idea is this: there exists a pure experience, an instantaneous present, a simple, unqualified actuality or existence, a pure this which is only virtually or potentially both object and subject. This "naïve" immediacy is there, and we carry out our action in it, "and the doubling of it in retrospection into a state of mind and a reality intended thereby, is just one of the acts. The 'state of mind,' first treated explicitly as such in retrospection, will stand corrected or confirmed, and the retrospective experience in its turn will get a similar treatment; but the immediate experience in its passing is always 'truth,' practical truth, something to act on, at its own movement" (James 1907/96: 12-3). Thus, the puzzle of how an identical room can be in two places (in my living in it as a physical place, and in my thinking about it), to cite a famous example by James, is solved by conceiving of the room as the place of intersection "of two processes, which connected it with different groups of associates respectively" (James 1907/96: 9): on the one hand the "subjective" biography of the house, and on the other, its "objective" history of which the room is a part. Concrete experience, "this here," is nothing but the terminus ad quem of a series of mental states, sensations, perceptions, emotions, expectations, and the terminus a quo of a series of possible "internal states" directed towards the future; but it is also the terminus ad quem of a succession of physical operations, such as flooring, painting, furnishing, heating, wallpapering, and the terminus a quo of possible concrete operations. Now, as James himself acknowledges,

The physical and the mental operations form curiously incompatible groups. As a room, the experience has occupied that spot and had that environment for thirty years. As your field of consciousness it may never have existed until now. As a room, attention will go on to discover endless new details in it. As your mental state merely, few new ones will emerge under attention's eye. As a room, it will take an earthquake, or a gang of men, and in any case a certain amount of time, to destroy it. As your subjective state, the closing of your eyes, or any instantaneous play of your fancy will suffice. In the real world, fire will consume it. In your mind, you can let fire play over it without effect. As an outer object, you must pay so much a 
month to inhabit it. As an inner content, you may occupy it for any length of time rent-free. (James 1907/96: 9) lines of order (James 1907/96:10); which, from the chaos of primal experiences, ${ }^{5}$ enables the experience itself to be structured, albeit in "curiously incompatible" ways (some passages possess the the curious stubbornness [...] of fact," others "the fluidity of fancy" (James 1907/96: 12), giving rise to "experienced relationships" (James 1907/96: 12n10) to different domains (or regions, to use a Husserlian term). ${ }^{6}$ These are structural chains which organize experience, giving it meaning and continuity, starting from a primal chaos, ${ }^{7}$ according to an order, both spatial and temporal, which renders actual experience (the here, the now) congruent in relation to the inactual horizons, both spatial ("there," "up there," "down there," etc.) and temporal ("then," "before," etc.), thereby offering continuity and stability to experience. By doing this, the thing in James undergoes a sort of "doubling up" (James 1907/96: 12), wholly absent in Husserl, according to the line of order in which it becomes inserted, "and all this without paradox or mystery, just as the same material thing may be both low and high, or small and great, or bad and good, because of its relations to opposite parts" (James 1907/96: 12-3). Subjective and objective thus become "functional attributes" (James 1907/96: 12), which make it possible to consider experience twice, according to the context in which it is inserted. From this point of view, consciousness does not connote an internal (or constitutive) relationship, but an external relationship. Or if we like, experience is not consciousness for James, or is not only consciousness. On the other hand, consciousness, "connotes a kind of external relation" (James 1907/96: 13) and not a particular "stuff": "But thoughts in the concrete are made of the same stuff as things are" (James 1907/96: 17; original emphasis).

\section{Pure Experience and Distinctio Rationis}

11 However, there are at least two important theoretical points which Husserl and James to share. The first is the absolute priority of the actuality of the here and now over the spatial and temporal background (or inactual horizon). The second, closely connected to the first, is the conception of the object of experience as capable of being broken down into parts: that is, the tacit adoption of a distinctio rationis. With regard to the first point, for Husserl "consciousness is nothing without impression" (Husserl 1893-1917/91: Appendix I, 163). If it is true that in time as it is experienced every pointnow becomes always and necessarily meditated by retention, it is also true there is no retention that is not rooted in a now. The primal impression, the present, the now, are the necessary fulcrum without which duration cannot unfold. In Husserl, therefore, we can certainly speak of the primacy of impressional consciousness, or of the datum.

Similarly, for James

The instant field of the present is at all times what I call the "pure" experience. It is only virtually or potentially either object or subject as yet. For the time being, it is plain, unqualified actuality, or existence, a simple that. In this naif immediacy it is of course valid; it is there, we act upon it [...] Consciousness connotes a kind of external relation, and does not denote a special stuff or way of being. (James 1907/96: 12-3)

13 The present, whether directly connected to action, as in James, or connected to the notion of evidence, as in Husserl, remains for both the pivot from which the lines of order (James) and the inactual horizon (Husserl) radiate. For this reason, the present

European Journal of Pragmatism and American Philosophy, IX-1 | 2017 
(or presentification) maintains for both an absolutely crucial and fundamental role. The centrality of the now, or the here, is also what enables both to conceive of experience as partly articulable. For Husserl, the priority (inherited simultaneously from scholastic tradition and from empiricism) of the notion of part is sanctioned by the adoption of the principle of the distinctio rationis; a principle which, in the case of the distinction between mind and body, is transformed into a distinctio realis or, as Husserl says, into a distinctio phenomenological (Husserl 1910-11/2006).

In principle, and precisely because they are essences, the essence of cogitatio and the essence of extensio have nothing to do with each other. In the essence of a pain or a pleasure, for example, there is absolutely no given relationship to a thing. For Husserl then, if this is the case, we can cut through the empirical relation between cogitatio and res, without thereby making an abstraction in the sense of Hume's distinctio realis: that is, in the sense of a distinction between essentially dependant and inseparable moments of a concretum. In this case too, Husserl's anti-psychologism does not only not deny, but in fact confirms the thesis of an absolute priority of consciousness. If the connection between experience and the person who possesses that experience is, ontologically speaking, contingent, the separation between consciousness and body is essential (which is why, without self-contradiction, we can, so to speak, cut the empirical bond between the experience and any existent thing, thereby making a certain "distinctio phenomenological," Husserl 1910-11/2006: \$13). In other words, the fact that it may be impossible to distinguish between experience and body does not rule out the essential possibility of their separation. It is precisely in this that difference between distinctio rationis and distinctio phenomenologica exists: the former concerns essentially separable moments (eg. color and extension in a sensible whole); the second, essentially separable moments (experiences and consciousness can be conceived of independently from their empirical relationship with a body).

James's perspective is founded as much as Husserl's on the ontological notion of part: for James, thought and thing are much more similar than they may at first appear, precisely by virtue of the fact that "both may have parts [...] and both may be complex or simple. Both are of kinds, can be compared, added and subtracted and arranged in serial orders" (James 1907/96: 14). If Husserl's mereological system attributes priority to the notion of part in relation to the notion of whole, the radical empiricism of James considers the notion of part to be secondary, in favour of the notion of relationship between parts. For the former, the thing of experience is, at least as far as the phenomenologico-static system is concerned, the fruit of foundational relationships between non-independent parts which give origin to wholes; for the latter, the thing of experience is given by the relational context in which the pure experiences are inserted. Nevertheless, what they share is the method of distinction or disjunction into - so to speak - "final" parts, whether these are non-independent, as in the case of Husserl, or independent - albeit neutral and expression of a "the materia prima of everything" (James 1907/96: 54), as in the case of James.

Husserl states:

There belongs to the essence of extension the ideal possibility of fragmentation. It is then evident that every fragmentation of the extension fragments the thing itself - i.e., splits it into pieces, each of which once again has the full thingly character, that of material thingness. (Husserl 1912/29: 33)

And James echoes him: 
Empiricism [...] lays the explanatory stress upon the part, the element, the individual, and treats the whole as a collection and the universal as an abstraction. My description of things, accordingly, starts with the parts and makes of the whole. (James 1907/96: 19-20)

Now, these shared traits (priority of the present and indispensability of the notion of part) are at risk of throwing out not only the phenomenological neutrality of "things themselves," but also Jamesian neutrality from that level of experience from which it claims not to detach itself. In other words, the principle of distinctio rationis, united to that of presentification, seems to deprive not only phenomenology, but also James's empiricism, of that radicalness and "purity" which in both cases constitutes an essential value. These principles in fact underlie a distancing, an inclination towards fixity which ends up freezing and (in James's eyes, unexpectedly) rendering "diaphanous" and "spectral" the primal flow of experience, the sole and effective terrain of neutrality. In this sense, Merleau-Ponty's critique of Husserl could apply with equal validity to James. For Merleau-Ponty, the reduction performed by phenomenological reflection ends up sapping the fullness of consciousness until it becomes disembodied, merely functional consciousness:

[t]o return to things themselves is to return to that world which precedes knowledge, of which knowledge always speaks, and in relation to which every scientific schematization is an abstract and derivative sign-language, as is geography in relation to the country-side in which we have learnt beforehand what a forest, a prairie or a river is. (Merleau-Ponty 1945/2002: ix-x)

With regard to the "living" territory in which we are immersed, both phenomenological reduction and the "functionalism" of James act as a map or chart, distancing us inevitably from the level of pure experience. "Fixity" and "fragmentation" are by no means original, but derived; they are products of that reflective style or "overview" which Merleau-Ponty traces in Husserl, but which I think it is also possible to detect in James. Presentification and "fragmentation" of experience do not express either a neutral stance or a radical empiricism; but they are endowed with a precise psychological stance, which is then structured into a theory, aimed less at an effective adhesion to experience than to a grasp or domination of it. Merleau-Ponty's question is indeed radical. Philosophy, he writes,

asks of our experience of the world what the world is before it is a thing one speaks of and which is taken for granted, before it has been reduced to a set of manageable, disposable significations; it directs this question to our mute life, it addresses itself to that compound of the world and of ourselves that precedes reflection, because the examination of the significations in themselves would give us the world reduced to our idealizations and our syntax. (Merleau-Ponty 1964/2004: 102)

To some extent, both Husserl and James seem to have avoided this question, although there are certainly some important hints in the two authors which move in this direction. As far as Husserl is concerned, the concept which perhaps most expresses the historicity and non-fragmentedness of the flow of experience is that of motivation, together with passive synthesis. Experience, for Husserl, is always manifested in a chain of motivations. This thesis constitutes a further argument against the thing in itself: indeed, precisely by being in itself, the thing withdraws from the uninterrupted flow (which, for Husserl, has no beginning and no end) of experiences and of their reciprocal nesting, or even their disconnection from one another, as happens in illusion, or even more radically, in hallucination. The thing in itself becomes unknowable and 
ungraspable precisely because it is not inserted into that motivational flux which renders experience naturally coherent and dependable, and only in certain cases (when motivation breaks down) deceptive; a flux which, however it comes into being, constitutes the only thing we have:

[i]t must always be born in mind here that whatever physical things are - the only physical things about which we can make statements, the only ones about the being or not being, the being thus or being otherwise, of which we can disagree and make rational decisions, they are as experienceable physical things. It is experience alone that prescribes their sense; and, since we are speaking of physical things in fact, it is actual experience alone which does so in its definitely ordered experiential concatenations. (Husserl 1913/83: 106) ${ }^{8}$

What stands behind the notion of motivation is the idea of thing as invariance in variations, referent to an indefinite progression of prospective modifications or convergent points of view which, precisely because they are convergent, allow the thing to maintain stability and identity. The notion of experience, in other words, contains with in itself an invariant structure of a type that is not so much (or not only) categorical (based on judgment), as principally motivational (perceptual). The transcendence of the object is thus guaranteed, from the phenomenological point of view, by the connections which experience manifests and by the perceptual coherence which results from it. Furthermore, the notion of motivation is valid in general: indeed, for the thing to be given, it is not so much necessary to isolate certain privileged and preferential motivational links, as specifically to sanction the existence in general of some motivational link. Once again, the notion of thing in itself highlights an impossibility: in this case, the epistemic impossibility of the thing that withdraws itself in principle from the motivational flux of experience. Similar elements are obviously also traceable in James, firstly in the centrality of the notion of flux of consciousness. Nevertheless, neither notion, that of motivation and that of flux, rules out the possibility, indeed the necessity, of a fixing and a segmentation.

\section{Radical Empiricism and Modification}

A possible alternative way forward consists in identifying, with respect to the material and mental (or representational) dimensions, not a distinction but a relationship of modification, in the sense that the latter can be conceived as a variation of the former. The almost oxymoronic expressions used by Merleau-Ponty, such as embodied mind, res viva, and flesh as "masse intérieurement travaillée," delineate a further concept of neutrality, founded less on the notion of determinative attribution than on that of modifying attribution. An embodied mind, a res viva, and a tormented matter are no longer in an authentic sense mind, res, matter, but something else. If we interpret these expressions in an attributive sense, there subsists a distinction - or, in the most extreme cases, a separation - between the mental and material dimensions. In the case where the expressions are instead interpreted as modifying, what occurs is a sort of ontological co-penetration capable of abandoning the static notion of part in favor of dynamic notions like those of tendency, force, friction, resistance. Based on what has been said thus far, it is possible to identify two meanings of invariance: an invariance in variation, which is static, and in which the notions of datum, determination and categorization play a fundamental role; and an invariance in transformation, which is evolutionary, more in tune with the variability and flexibility of the living thing than 
with the stability and invariance of the inert, closer to a transformative process, in itself absolutely indivisible and not fragmentable, than to the identification of bundles of characteristics.

Physical matter as a network of relationships will in the end be replaced by what for Merleau-Ponty is flesh (chair), a notion which guarantees the simultaneous presence of a flux of consciousness and matter, of subjective and objective existence, as happens in the famous example, proposed by Merleau-Ponty but in fact taken from Husserl himself, of the phenomenon of the hand touching and being touched. Indeed, for Merleau-Ponty the thing is flesh, and not simply body: that is, not simple extension or bodily surface covered by determined qualities; similarly, sensation is not mere reception of qualities, but vital inherence; it does not offer inert qualities but active, dynamic properties endowed with depth because they contribute to life. According Merleau-Ponty,

there are two ways of being mistaken about quality: one is to make it into an element of consciousness, when in fact it is an object for consciousness, to treat it as an incommunicable impression, whereas it always has a meaning; the other is to think that this meaning and this object, at the level of quality, are fully developed and determinate. (Merleau-Ponty 1945/2002: 4)

And again:

The pure quale would be given to us only if the world were a spectacle and one's own body a mechanism with which some impartial mind made itself acquainted. Sense experience, on the other hand, invests the quality with vital value, grasping it first in its meaning for us, for that heavy mass which is our body, whence it comes about that it always involves a reference to the body. (Merleau-Ponty 1945/2002: 46)

This is a new, extremely radical form of anti-psychologism and anti-dualism, in which the notions which emerge (feeling, flesh, friction, tendency) are characterized by a profound and constitutive bilaterality and dynamism: that is, a structure which is capable of maintaining the now foundational ideas of transformation, interweaving, copenetration. What is more, James himself was perfectly clear that the aim of radical empiricism is the analysis of the complexity, not of consciousness nor or matter, but of the living thing, when he states that

I am as confident as I am of anything that, in myself, the stream of thinking [...] is only a careless name for what, when scrutinized, reveals itself to consist chiefly of the stream of my breathing. The "I think" which Kant said must be able to accompany all my objects, is the 'I breathe' which actually does accompany them [...]. Breath moving outwards, between the glottis and the nostrils, is, I am persuaded, the essence out of which philosophers have constructed the entity known to them as consciousness. (James 1907/96: 15-6) 


\section{BIBLIOGRAPHY}

CARNAP R., (1921-26), “Vom Chaos zur Wirklichkeit” (mit Notizen zum Konstitution-System), Box 81a, Folder 5, Rudolf Carnap Papers, 1905-1970, ASP.1974.01, Special Collections Department, University of Pittsburgh.

JAMES W., (1907/96), Essays in Radical Empiricism, Lincoln, Nebraska, University of Nebraska Press. HUSSERL E., (1899-1900a), Prolegomena to Pure Logic, Halle Niemeyer; trans., Logical Investigations, London, Routledge, 1973

HUSSERL E., (1899-1900b), Logische Untersuchungen Vol II/1, Untesuchungen zur Pänomenologie und Theorie der Erkenntnis, Halle Niemeyer; trans. Logical Investigations, London, Routledge, 1973 HUSSERL E., (1900-01), Logische Untersuchungen, Halle Max Niemeyer; trans. Logical Investigations, Vol. II, London and New York, Routledge, 2001.

HUSSERL E., (1893-1917/91), Zur Phänomenologie des Inneren Zeitbewusstseins, The Hague, Martinus Nijhoff; trans. On the Phenomenology of the Consciousness of Internal Time, Boston, London, Kluwer, Dordrecht, Vol. IV.

HUSSERL E., (1910-11/2006), Aus den Vorlesungen, Grundprobleme der Phänomenologie, Wintersemester 1910/1911, in Zur Phänomenologie der Intersubjektivität, Husserliana XIII; trans. The Basic Problems of Phenomenology, From the Lectures, Winter Semester, 1910-11, Springer, Dordrecht.

HUSSERL E., (1912-29), Ideen zu einer reinen Phänomenologie und einer phänomenologischen Philosophie, Zweites Buch, Phänomenologischen Untersuchungen zur Konstitution, Husserliana IV, Den Haag, Martinus Nijhoff; trans., Ideas Pertaining to a Pure Phenomenology and to a Phenomenological Philosophy, Second Book, Studies in the Phenomenology of Constitution, Boston, London, Kluwer, Dordrecht, 1989

HUSSERL E., (1913/83), Ideen zu einer reinen Phänomenologie und einer phänomenologischen Philosophie: Allgemeine Einführung in die reine Phänomenologie, Husserliana, III/1 e III/2, Den Haag, Martinus Nijhoff, 1976; trans., Ideas Pertaining a Pure Phenomenology and to a Phenomenological Philosophy, First Book, General Introduction to a Pure Phenomenology, Martinus Nijhoff, The Hague, Boston, Lancaster.

HUSSERL E., (1920-26), Analysen zur passiven Synthesis, Dordrecht, Kluwer Academic Publishers, 1966; trans., Analyses Concerning Passive and Active Synthesis: Lectures on Transcendental Logic, Boston, London, Kluwer, Dordrecht, 2001.

HUSSERL E., (1921-28), Zur Phänomenologie der Intersubjektivität, Zweiter Teil, Husserliana XIV (Hua XIV), The Hague, Martinus Nijhoff, 1973.

HUSSERL E., (1937), Die Krisis der europäischen Wissenschaften und die transzendentale Phänomenologie, Husserliana VI, 1959; trans., The Crisis of European Sciences and Transcendental Phenomenology, Evanston, Illinois, Norwestern University Press.

HUSSERL E., (1966), Die Ideen der Phänomenologie, Den Haag, Martinus Nijhoff; trans., The Idea of Phenomenology, Den Haag, Martinus Nijhoff.

MERLEAU-PONTY M., (1945/2002), Phénoménologie de la perception, Paris, Éditions Gallimard; trans., Phenomenology of Perception, London, Routledge.

MERLEAU-PONTY M., (1964/2004), Le visible et l'invisible, Paris, Éditions Gallimard; trans., The Visible and the Invisible, London, Routledge. 
MILL J. S., (1965), An Examination of Sir W. Hamilton's Philosophy, London.

\section{NOTES}

1. This is the solution that can be found in Mill 1965.

2. And not bilateral, as in the case of extension and colour; it is in fact possible to have an experience without a thing, as in the case of feelings, or more generally of all non-intentional experiences.

3. 'The dualism connoted by such double-barrelled terms as 'experience,' 'phenomenon,' 'datum,' 'Vorfindung' - terms which, in philosophy at any rate, tend more and more to replace the single-barrelled terms of 'thought' and 'thing' - that dualism, I say, is still preserved in this account, but reinterpreted, so that, instead of being mysterious and elusive, it becomes verifiable and concrete" (James 1907/96: 8).

4. "Experience, I believe, has no such inner duplicity; and the separation of it into consciousness and content comes, not by way of subtraction, but by way of addition" (James 1907/96: 8).

5. This idea is also present in Carnap 1921-26.

6. An another meaning of neutrality is revealed in the thesis of the ontological parity between percepts and concepts, according to which we should not believe "that the merely thought-of object is hid away inside of the thinking. The object of which I think, and of whose existence I take cognizance without letting it now work upon my senses, occupies its definite place in the outer world as much as does the object which Idirectly" (James 1907/96: 11). Thus, for James as for Husserl, there is a clear distinction between thinking [Gedanke] and thought [Gedachtes]: "but even were they centaurs and golden mountains, they still would be 'off there,' in fairy land, and not 'inside' of ourselves" (James 1907/96: 11).

7. "Here as elsewhere the relations are of course experienced relations, members of the same originally chaotic manifold of non-perceptual experience of which the related terms themselves are parts" (James 1907/96: 11n10). The topic of passing from chaos to structure is also present in Carnap and in Mach.

8. In this sense, it therefore seems legitimate to contrast the genetic-motivational nexus with the causal nexus.

\section{ABSTRACTS}

Both the phenomenology of Husserl and the pragmatist phenomenology of James can be categorized by the formula "radical empiricism," which is explicit in James and implicit, but no less pervasive, in Husserl. For both of them, radical empiricism is additionally conjoined with an equally radical anti-psychologism. The problem is that the two terms "radical empiricism" and "anti-psychologism" take on a radically different meaning in the two authors. This essay aims to investigate the structural differences between two perspectives that, while following completely different courses, seem to share the same objective: to elaborate a philosophy which at no point moves away from the experiential plane. 
AUTHOR

ROBERTA LANFREDINI

Università degli Studi di Firenze

roberta.lanfredini[at]unifi.it 